\title{
Divided attention, aging, and priming in exemplar generation and category verification
}

\author{
LEAH L. LIGHT \\ Pitzer College, Claremont, Califormia \\ and \\ MATTHEW W. PRULL and ROBERT F. KENNISON \\ Claremont Graduate University, Claremont, California
}

\begin{abstract}
Transfer-appropriate processing theories differentiate between conceptual- and perceptual-priming tasks. The former are said to be influenced by the nature of processing engaged in at study, but not by changes in modality between study and test; the latter are sensitive to changes in format between study and test, but not to variations in the extent of semantic processing at study. In the present experiments, we examined the effects of divided attention and aging on priming in exemplar generation and category verification, two tasks that require access to semantic information at test. Manipulations of attention during encoding affected the extent of priming in exemplar generation, but not in category verification. Priming effects were similar in young and older adults in exemplar generation following study in both full and divided attention. Although older adults did not demonstrate priming in category verification in one experiment, no effects of age or divided attention were observed in a second experiment. In addition, priming in category verification was unaffected by varying the level of processing at encoding. However, the absence of levels-of-processing and attention effects in category verification does not signal that priming in this task has a perceptual basis; priming in category verification was insensitive to modality shifts between study and test. The implications of these findings for theories of priming and cognitive aging are considered.
\end{abstract}

Division of attention during encoding is well known to have negative consequences for performance on direct measures of memory, such as recall and recognition, that involve deliberate recollection of prior study episodes (e.g., Craik, Govoni, Naveh-Benjamin, \& Anderson, 1996; Fisk \& Schneider, 1984; Kellogg, 1980; Parkin, Reid, \& Russo, 1990; Weldon \& Jackson-Barrett, 1993). However, the consequences of dividing attention during encoding on indirect memory tasks, in which the task instructions do not mention the relation between the task to be performed and the prior study episodes, are less well understood. It is, for instance, unclear whether we should expect the effects of dividing attention to be uniform across all classes of indirect memory tasks.

Recent research on the consequences of dividing attention for indirect measures of memory has been guided largely by the transfer-appropriate processing frame-

This research was reported, in part, at the Annual Meeting of the Psychonomic Society, 1995, Los Angeles, and at the 1996 International Conference on Memory in Abano Terme, Italy. It was supported by Grant R37 AG02452 from the National Institute on Aging. We gratefully thank Maureen Schmitter-Edgecombe and Cathy McEvoy for helpful feedback on earlier versions of the paper and Eve Bernstein, Marisa Collett, and Rebecca Soffer for assistance in data collection and analysis. M.W.P. is now at the Department of Psychology, Whitman College. Correspondence concerning this article should be addressed to L. L. Light, Department of Psychology, Pitzer College, 1050 N. Mills Avenue, Claremont, CA 91711 (e-mail: llight@hal.pitzer.edu). work. Blaxton (1989) and Srinivas and Roediger (1990) have proposed that some measures of memory, whether direct or indirect, are perceptually driven, whereas other measures are conceptually driven. Perceptually driven indirect measures, such as perceptual identification and word-fragment completion, are generally insensitive to levels-of-processing manipulations during encoding but are affected by changes of format (e.g., from the auditory to the visual modality or from pictures to words) between study and test (see, e.g. Jacoby \& Dallas, 1981; Roediger, Weldon, Stadler, \& Riegler, 1992). Conversely, conceptually driven indirect measures, such as generating category exemplars and answering general knowledge questions, like recall and recognition, benefit from elaborative encoding and are insensitive to format changes between study and test (e.g., Hamann, 1990; Monti et al., 1996; Rappold \& Hashtroudi, 1991; Rastle \& Burke, 1996; Srinivas \& Roediger, 1990). Priming on perceptually driven tests might not be expected to vary with attention during encoding, whereas priming in conceptual tasks might be expected to suffer to the extent that dividing attention disrupts semantic processing.

The empirical findings with respect to the effects of dividing attention on priming are not wholly consistent with this position. Some studies have found that dividing attention at study does not reduce the amount of repetition priming observed in tasks thought to depend primarily on perceptual processing, such as perceptual identifica- 
tion, lexical decision, word-fragment completion, wordstem completion, or picture-fragment completion (Kellogg, Newcombe, Kammer, \& Schmitt, 1996; Mulligan, 1997; Mulligan \& Hartman, 1996; Parkin et al., 1990; Parkin \& Russo, 1990; Schmitter-Edgecombe, 1996). Other studies have found reductions in repetition priming on such tasks following study in divided attention conditions (Hawley \& Johnston, 1991; Weldon \& JacksonBarrett, 1993). And still others have had both outcomes, depending on the particular arrangements of the study and test conditions (Gabrieli et al., 1995; Mulligan \& Hornstein, 2000; Wolters \& Prinsen, 1997). Light and Prull (1995) also found a negative effect of divided attention on priming in word naming, a task that appears to be largely perceptually driven (MacLeod, 1996).

The effects of dividing attention during study have been investigated in only a few conceptual-priming tasks. Here too, the results have been inconsistent. Some studies report that dividing attention reduces priming in exemplar generation (Gabrieli et al., 1995; Gabrieli et al., 1999; Mulligan, 1997; Mulligan \& Hartman, 1996), whereas others do not (Isingrini, Vazou, \& Leroy, 1995; Schmitter-Edgecombe, 1996). Although Koriat and Feuerstein (1976) found a null effect of dividing attention on priming in word association, another task that involves access to semantic information, Mulligan (1998) reported that digit monitoring reduced priming in this task. In a report that became available while our own investigations were in progress, Gabrieli et al. (1999) presented evidence that digit monitoring does not reduce priming in a category verification task similar to one we used in Experiments 2 and 3 . As will be discussed below, however, the status of semantic verification tasks as conceptual or perceptual is open to debate.

At present, the conditions that govern the effects of dividing attention on priming cannot be specified with any certainty. One factor that may play a role is the difficulty of dividing attention during study. For instance, the study tasks used by Parkin and Russo (1990) and Parkin et al. (1990) were self-paced, so switching attention from task to task may have been easy. In the Isingrini et al. (1995) and Schmitter-Edgecombe (1996) studies, the presentation rate was slow ( $5 \mathrm{sec}$ per item), so here, too, switching attention between word encoding and the divided attention task may have been fairly easy. Thus, in these experiments, the concurrent task may not have been sufficiently attention demanding. Several studies bear out this conjecture. Hard, but not easy, divided attention tasks reduce priming in exemplar generation (Mulligan, 1997), word-stem completion (Wolters \& Prinsen, 1997), and perceptual identification (Mulligan \& Hornstein, 2000). This strongly suggests that conclusions about the role of attention in any given indirect measure of memory can be drawn only after a number of manipulations of attention have been tried.

In this article, we report a series of experiments in which the effects of divided attention on two tasks, exemplar generation and category verification, were investigated.
In the exemplar generation experiments, people saw a list of words drawn from several taxonomic categories. During study, no mention was made of the fact that some words on the lists came from particular categories. At test, people were given the names of categories from which list members were drawn, as well as new categories not represented on the study list. They were asked to generate five members for each category. Priming was defined as the increase in the likelihood of producing words that had been studied over those that had not been studied. In the category verification experiments, the indirect task was to decide whether a word belonged to a particular category. Priming was defined as the difference between studied and unstudied items in response time (RT) to decide that an instance was a member of a particular category. The divided attention task that we used was a difficult one. Words were presented flanked by single digits, and the participants were asked to decide whether the sum of the digits was odd or even. Given that we have previously found this task to reduce priming in word naming (Light \& Prull, 1995) and that a similar, probably less demanding, arithmetic task reduces priming in perceptual identification of words even with a relatively long 3-sec presentation duration (Mulligan \& Hornstein, 2000), this task was expected to provide a good test of the sensitivity of both exemplar generation and category verification to divided attention.

As was discussed above, exemplar generation fits well within the definition offered by Blaxton (1989) for a conceptual-priming task, and we predicted divided attention effects in this task. Less is known, however, about the nature of priming in semantic classification tasks. There is some evidence that priming in such tasks is sensitive to the nature of the encoding tasks used, but not to a change in format between study and test (Vriezen, Moscovitch, \& Bellos, 1995), suggesting that semantic classification is indeed conceptually driven. On the other hand, Vaidya et al. (1997) found that priming in two semantic classification tasks-namely, verification of category membership and abstract/concrete judgments - was insensitive to manipulations of both levels of processing and encoding and match between study and test modalities. The experimental procedures in these investigations differed in a number of ways, making predictions based on their outcomes problematic. Nonetheless, Gabrieli et al. (1999) and Vaidya et al. have suggested that what differentiates tasks that are sensitive to attentional manipulations from those that are not is whether response production is required or whether only identification of a stimulus or one of its properties is needed. This hypothesis predicts that the divided attention task used here should attenuate priming for exemplar generation, but not for category verification. ${ }^{1}$

We report a total of four experiments. In Experiment 1, we compared the effects of dividing attention on priming in exemplar generation in young and older adults. Experiments 2 and 3 compared the effects of divided attention on priming in category verification in young and 
older adults. Finally, Experiment 4 addressed the issue of whether priming in category verification is influenced by levels of processing or input modality during study with our procedures.

We have included older adults in Experiments 1-3 for two reasons. First, normal aging is accompanied by reduced accuracy on direct measures of memory, but indirect measures of memory often yield only small, typically unreliable, age differences. In a meta-analysis of priming studies comparing young and older adults, La Voie and Light (1994) found a smaller effect size $(0.30)$ for repetition priming than for either recognition $(0.50)$ or recall (0.97). This meta-analysis, however, included primarily perceptual- rather than conceptual-priming tasks. It has been suggested that older adults might have relatively unimpaired priming on perceptual tasks while showing reduced conceptual priming (Jelicic, 1995; Rybash, 1996). Nonetheless, the extant literature suggests that age differences are not reliably obtained on tasks that meet Srinivas and Roediger's (1990) criteria for conceptualpriming tasks. For instance, young and older adults show similar benefits from prior exposure to answers to general knowledge questions (Rastle \& Burke, 1996; Small, Hultsch, \& Masson, 1995), show similar priming in a word association task (McEvoy, Holley, \& Nelson, 1995), and, with two exceptions, show similar levels of priming in exemplar generation (Isingrini et al., 1995; Light \& Albertson, 1989; Maki \& Knopman, 1996; Monti et al., 1996). The two exceptions are studies by Grober, Gitlin, Bang, and Buschke (1992) and Jelicic, Craik, and Moscovitch (1996); in these studies, some or all of the participants engaged in deliberate recollection tasks prior to the exemplar generation test, possibly predisposing them to treat this task as a direct measure of memory. To date, only a few studies have compared priming in young and older adults in semantic judgment tasks (Hamberger \& Friedman, 1992; Rabbitt, 1982, 1984); no age differences in priming were found. These studies, however, used a continuous judgment task and computed priming by subtracting the latency for the second presentation of an item from the latency for the first presentation rather than from an unstudied baseline, a method that confounds priming with warm-up benefits. Thus, Experiments 2 and 3 extend the range of conceptual-priming tasks studied in this population, using techniques that are more similar to standard priming paradigms.

Second, there have been few studies examining the effects of divided attention on priming in older adults. It is frequently claimed that older adults have limited attentional resources, which makes it more difficult for them to divide attention (see Hartley, 1992, and Salthouse, 1991, for reviews). Thus, it might be anticipated that dividing attention during study would have a differential impact on memory in young and older adults. The data do not fully support this claim, however, because studies of recall and recognition have not consistently found greater impairment for older adults under divided attention con- ditions (see Anderson, Craik, and Naveh-Benjamin, 1998, for a review). There have been only a few studies dealing with the joint effects of age and divided attention on indirect measures of memory. Isingrini et al. (1995) found effects of neither of these variables on priming in exemplar generation, but as was noted above, it is possible that their presentation rate was slow enough to permit some attention switching. Light and Prull (1995) found that divided attention reduced priming on a word-naming task equally in young and older adults. Experiments 1-3 provided additional opportunities to explore this question.

\section{EXPERIMENT 1}

Experiment 1 compared the effects of divided attention on exemplar generation and cued recall in young and older adults. Isingrini et al. (1995) reported null effects of both divided attention and aging on priming in exemplar generation. Because it is now clear that priming in the exemplar generation task is sensitive to attentional manipulations, but only when the divided attention task is sufficiently demanding, further examination of the joint effects of age and attention is warranted. Views that older adults have reduced attentional resources that limit encoding of information predict that dividing attention should have disproportionate effects on performance in both direct and indirect memory tests in this population. On the other hand, two recently published investigations have reported no age differences in the effects of encoding manipulations on priming in category exemplar generation (Maki \& Knopman, 1996; Monti et al., 1996). On the basis of these findings, and assuming that dividing attention reduces semantic processing during study, it would not be surprising to find similar effects of dividing attention across age.

\section{Method}

Participants. Twenty-four young adults (14 females and 10 males; $M$ age $=20.29$, range $=17-27)$ and 24 older adults $(17 \mathrm{fe}$ males and 7 males; $M$ age $=72.50$, range $=65-81$ ) participated in Experiment 1 in exchange for $\$ 12$. All the participants in this experiment (and in the remaining ones as well) completed a demographic questionnaire and a small battery of cognitive measures administered for purposes of characterizing the samples. The younger adults were drawn from the student population at the Claremont Colleges, the older adults from the local community. The older adults reported more years of education $(M=16.69)$ than did the young adults $[M=14.92 ; t(46)=3.46]$. They also rated themselves as healthier than the young adults on a 10-point scale in which a value of 10 represented excellent health $[M$ older $=8.46, M$ young $=7.08$; $t(46)=2.25]$. Older adults obtained higher scores than the young on a 25 -item version of the Nelson-Denny (1960) vocabulary test $[M$ older $=22.50, M$ young $=16.17 ; t(46)=9.58]$. Also, when asked to produce as many words as they could, beginning with the letter $F$ (excluding proper names), in $60 \mathrm{sec}$, older adults produced slightly, but not reliably, more words than did young adults $[M$ young $=$ $15.79, M$ old $=17.04 ; t(46)=0.95$ ]. Older adults scored slightly, but not significantly, lower than young adults on the WAIS digit span test, with means of 6.67 and 7.17 , respectively, for the forward subtest $[t(46)=1.23]$, and 5.42 and 5.75 , respectively, for the back- 
ward subtest $[t(46)=0.83]$. This pattern of findings is fairly typical for comparisons of young and older adults (see Salthouse, 1991).

In addition, data from 3 young and 7 older adults were discarded Of the young adults, 1 was not a native speaker of English, 1 proved to be older than 35 (our upper limit for this group), and 1 was replaced because of an experimental error. Of the older adults, 1 was not a native speaker of English, 1 had recently had a minor stroke 4 misunderstood the instructions for one or more tasks, and 1 was unable to perform the divided attention task.

Materials and Design. Two exemplars from each of 30 categories were selected from the Battig and Montague (1969) norms. Ten categories were assigned to each of three lists. Exemplars in the three lists were similar in frequency of occurrence in the Francis and Kučera (1982) norms ( $M=22.92$ occurrences per million, range $=$ $0-327)$, ordinal position in the Battig and Montague (1969) norms $(M=10.52$, range $=5-26)$, number of letters $(M=6.15$, range $=$ $3-9)$, and number of syllables $(M=2.10$, range $=1-4)$. An additional 20 filler words were assigned to each list, increasing list length to 40 words. The filler words were mostly nouns, although there were a few adjectives (e.g., mighty, vital), and verbs (e.g., prevail, attain); none was an instance of an experimental category. The first 5 and last 5 words in each list were fillers. The remaining words in the list were randomized, with the restriction that no more than 3 experimental words could appear in succession.

The three lists were rotated through three study conditions-full attention, divided attention, and unstudied. Half of the participants received the full attention list, followed by the divided attention list, whereas the other half received the lists in the opposite order. Finally, for half of the participants, one half of the categories in each study condition was included in the category exemplar test, whereas the other half was in the category-cued recall test; for the other half of the participants, this assignment was reversed. The design of Experiment 1 was thus 2 (age) $\times 3$ (study conditions) $\times 2$ (study order) $\times 2$ (test list assignment). Two participants in each age group were tested in each of the 12 cells needed for counterbalancing.

Procedure. The participants were first given practice in adding 40 pairs of single-digit numbers. The numbers in each pair were separated by seven blank spaces, and each pair appeared centered on the screen for $3 \mathrm{sec}$. The task was to quickly add the number pair during the time it was displayed and note the sum. If the sum was even, the / key, which was marked even, was pressed. If it was odd, the $z$ key, marked odd, was pressed.

After number addition practice, each participant studied two lists of words accompanied by intentional encoding instructions. Words always appeared centered on the computer screen for $3 \mathrm{sec}$, with no blank screen between words. In the full attention task, the participants evaluated the pleasantness of words as they appeared, pressing the $z$ key (marked pleasant) if they found the meaning of the word to be pleasant and the / key (marked unpleasant) if not. Three practice trials preceded list presentation for the full attention condition. The participants were further instructed to remember the words for a later memory test. In the divided attention condition, each word was flanked by a pair of single-digit numbers (e.g., 5 BRONZE 7). The participants again judged words for pleasantness, using the keyboard keys, and tried to remember them; they also added the flanking numbers appearing with each word and reported aloud whether the sums were odd or even. The participants were instructed that the number addition task was their primary task, that they should treat it as the most important task, and that rating words for pleasantness should be considered a secondary task. Twenty practice trials preceded the actual divided attention trials; the practice trials used filler words different than those used in any of the experimental lists themselves.

After the two lists were presented, a pencil-and-paper task followed, in which the participants were given a set of questions about a small grid of letters printed at the top of the page. These questions required searching through the letter grid to identify letters in particular locations or to consider what letters would appear if certain lines or rows of the grid changed in specific ways. This was used as a filler task to prevent rehearsal of the study items. The participants were given 3 min to work on the grid task.

The exemplar generation and cued recall tests were then adminstered, with the exemplar generation task always occurring first. The two tests were separated by administration of a strategy questionnaire (see below). For the exemplar generation test, 20 category names were presented one at a time for $15 \mathrm{sec}$ each. Half of the category names represented the superordinate category labels for words in the two study lists (five categories per list), and half named new categories. Of the 10 new category names, 5 were from categories on the unstudied experimental list, and 5 were names of filler categories (categories that were not represented in any study list). For each category label, the participants were to name aloud the first five exemplars of that category that came to mind. A computer-generated beep sounded during the last $400 \mathrm{msec}$ of each 15 -sec generation period to signal the impending presentation of the next category name. Presentation of category names in the cued recall test followed a format identical to that of the category exemplar test, except that the participants were asked to use the category names as cues to recall words seen previously in either list; the participants were told that some categories would contain words that had been studied earlier but that other categories were new and did not contain previously studied words. The filler category names were different on the exemplar generation and cued recall tests. The responses for each test were tape recorded for later scoring.

The strategy questionnaire consisted of a graded series of questions to determine whether deliberate guessing strategies were used in the category exemplar task (e.g., "While doing the task in which you generated words belonging to different categories, did you deliberately guess with words from any of the study lists when you were not sure what to generate?"). Six young and 2 older adults in Experiment 1 reported using deliberate guessing strategies. However, when we carried out analyses of exemplar generation and cued recall data for just those participants who denied deliberately guessing studied words, the means of variables of interest changed very little, and the patterns of significant effects remained the same. Similar outcomes were obtained for Experiments 2 and 3 when we queried people about strategy use in category verification. Hence, the issue of guessing strategies is not discussed further. ${ }^{2}$

The experimental session concluded with the completion of a demographics sheet, administration of the WAIS digit span subtest, a 25 -item version of the Nelson-Denny (1960) vocabulary test, and a verbal fluency task. The verbal fluency task involved saying aloud as many words as could be retrieved in $1 \mathrm{~min}$, beginning with the letter $\mathrm{F}$ and excluding proper nouns. The responses were tape recorded and transcribed at a later time. The entire session lasted about $1 \mathrm{~h}$.

\section{Results}

Divided attention. In the 40-item experimental block, young and older adults had similar numbers of correct responses on the odd/even judgment task $[M$ young $=$ $37.67, M$ old $=37.29 ; t(46)=0.40]$. However, on the pleasantness rating task, the young adults made more responses to words than did the old $[M$ young $=36.33$, $M$ old $=33.75 ; t(46)=2.46]$. Information about performance on the pleasantness judgment task in the full attention block is not available for Experiment 1 owing to a programming error; however, in both Experiments 2 and 3 , performance on this task in the full attention study 
condition was at ceiling (.98 for young adults and .97 for older adults in each experiment) with the same task.

Exemplar generation. Inasmuch as comparison of priming in exemplar generation in different populations is complicated if the numbers of items generated by the different groups are not equal, we first checked to see whether this was the case here. Because there was a maximum of five responses that could be made to each of five category names per condition, the maximum score for any condition was 25 . Happily, older adults generated about as many words overall (23.22) as did young adults (22.72).

Mean proportions of exemplars generated as a function of the three encoding conditions are displayed in Table 1. A 2 (age) $\times 3$ (encoding condition: full attention, divided attention, new) analysis of variance (ANOVA), with repeated measures on the last factor, produced a main effect of encoding condition $\left[F(2,92)=29.10, M S_{\mathrm{e}}=\right.$ $0.017]$ but no effect of age $\left[F(1,46)=1.81, M S_{\mathrm{e}}=0.020\right]$ and no interaction between age and encoding condition $\left[F(2,92)=0.91, M S_{\mathrm{e}}=0.017\right]$. Words studied under full attention (.329) were generated more often than words studied under divided attention $[.250 ; F(1,46)=8.48$, $\left.M S_{\mathrm{e}}=0.018\right]$. Divided attention words were generated significantly more often than baseline $[.127 ; F(1,46)=$ $\left.25.28, M S_{\mathrm{e}}=0.014\right]$.

We conducted two further analyses of the data displayed in Table 1. First, we were concerned that young adults produced a significantly higher baseline response rate (.163) than did older adults (.092). This difference was significant $\left[F(1,46)=4.36, M S_{\mathrm{e}}=0.014\right]$. To correct for this, we used priming scores created by subtracting the baseline generation rate from the generation rate in the full and divided attention conditions. A 2 (age) $\times 2$ (priming: full attention, divided attention) ANOVA, with repeated measures on the last factor, generated a significant effect only of study condition. Full attention produced more priming (.202) than did divided attention (.123). Neither the effect of age $\left[F(1,46)=1.65, M S_{\mathrm{e}}=0.049\right]$ nor the interaction between age and priming condition $[F(1,46)=$ $\left.0.21, M S_{\mathrm{e}}=0.018\right]$ was significant

Second, we were concerned that young adults produced more pleasantness judgments than did older adults in the divided attention condition during list study. Because older adults did not differ from young adults in priming in the present experiment, we could argue (rather circularly) that they were probably engaging in the pleasantness judgment task but not actually making a response for some items. To the extent, however, that making a response is itself attention demanding, older adults might have some advantage in the divided attention condition. We created subgroups of 20 young and 20 older adults that were matched on performance on both addition task accuracy and frequency of pleasantness judgments. For the pleasantness judgment task, the young subgroup had a mean of 35.60 , and the old subgroup had a mean of 35.10 $[t(38)=0.63]$. On the addition task, the means of the young and older adults were 37.30 and 38.00 , respectively $[t(38)=0.73]$. Means for the category exemplar generation and cued recall tasks are shown in Table 1. An ANOVA for the matched subsamples produced exactly the same pattern of results as did the analysis of the full samples and is therefore not discussed in detail.

Cued recall. Results from the cued recall task are displayed in Table 1. Because no participant produced a target word as an intrusion, we analyzed the data with a 2 (age) $\times 2$ (encoding condition: full attention, divided attention) ANOVA. The main effect of age was significant $\left[F(1,46)=6.80, M S_{\mathrm{e}}=0.059\right]$; young adults recalled more words $(.392)$ than did older adults $(.263)$. The main effect of condition was significant $[F(1,46)=54.06$, $\left.M S_{\mathrm{e}}=0.022\right]$; full attention words $(.438)$ were recalled more often than divided attention words $(.217)$. There was also a significant interaction between age and encoding condition $\left[F(1,46)=4.33, M S_{\mathrm{e}}=0.022\right]$. The difference between young and older participants was greater in the full attention condition than in the divided

Table 1

Mean Proportion (With Standard Deviation) of Target Words

Produced on Category Exemplar Generation and Category-Cued Recall Tasks in Experiment 1

\begin{tabular}{|c|c|c|c|c|c|c|c|c|c|c|c|}
\hline \multirow[b]{3}{*}{ Group } & \multicolumn{6}{|c|}{ Exemplar Generation } & \multicolumn{5}{|c|}{ Cued Recall } \\
\hline & \multicolumn{2}{|c|}{ FA } & \multicolumn{2}{|c|}{$\mathrm{DA}$} & \multicolumn{2}{|c|}{ New } & \multicolumn{2}{|c|}{ FA } & \multicolumn{2}{|c|}{$\mathrm{DA}$} & \multirow[b]{2}{*}{ New } \\
\hline & $M$ & $S D$ & $M$ & $S D$ & $M$ & $S D$ & $M$ & $S D$ & $M$ & $S D$ & \\
\hline \multicolumn{12}{|c|}{ All Participants } \\
\hline Young & .329 & .146 & .263 & .092 & .163 & .150 & .533 & .218 & .250 & .177 & .000 \\
\hline Older & .329 & .176 & .238 & .144 & .092 & .072 & .342 & .226 & .183 & .176 & .000 \\
\hline Mean & .329 & & .250 & & .127 & & .438 & & .217 & & .000 \\
\hline \multicolumn{12}{|c|}{ Matched Subsamples } \\
\hline Young & .320 & .147 & .265 & .099 & .175 & .152 & .535 & .225 & .235 & .169 & .000 \\
\hline Old & .320 & .170 & .240 & .154 & .090 & .079 & .345 & .233 & .185 & .190 & .000 \\
\hline Mean & .320 & & .253 & & .133 & & .440 & & .210 & & .000 \\
\hline
\end{tabular}


attention condition. Indeed, when we analyzed the interaction further, we found that the difference between young and old in the full attention condition was significant $\left[F(1,46)=8.93, M S_{\mathrm{e}}=0.049\right]$, but for divided attention it was not $\left[F(1,46)=1.71, M S_{\mathrm{e}}=0.031, p=.20\right]$.

We also carried out an ANOVA of the cued recall data of subgroups matched on addition and number of pleasantness judgments made in the divided attention condition. The means for the matched subgroups are provided in Table 1. As can be seen by inspecting these means, they were virtually identical to those of the full groups, and an ANOVA produced the same pattern of significant effects.

\section{Discussion}

The results of Experiment 1 are straightforward. Divided attention reduced the extent of priming in exemplar generation and did so not only when data from the full samples were analyzed, but also when just the data from nonguessing participants were considered. As in most prior studies of exemplar generation in young and older adults, the amount of priming did not differ with age. In this respect, the results of Experiment 1 replicate those of Isingrini et al. (1995). The divided attention task was quite difficult for older adults, as was evidenced by the fact that they made fewer pleasantness judgments during study than did young adults. Nevertheless, matching young and older adults on accuracy in the number addition and pleasantness judgment tasks during study did not affect the pattern of results obtained. In short, although we succeeded in producing a situation in which divided attention affected priming in exemplar generation and in which dividing attention appears to have been reasonably challenging for older adults, there was no indication of a greater divided attention decrement in priming for older adults.

Divided attention reduced cued recall, as was anticipated. Older adults recalled fewer words than did young adults, also as was anticipated. The dissociation between exemplar generation and cued recall for young and older adults replicates earlier work in our laboratory (Light \& Albertson, 1989) and in other laboratories (Isingrini et al., 1995; Maki \& Knopman, 1996; Monti et al., 1996). Divided attention had a larger effect on cued recall for young participants than for older participants. A similar pattern of cued recall results was reported by Isingrini et al. (1995). However, these findings are not readily interpretable, inasmuch as cued recall was not matched across age in the full attention condition in Isingrini et al. or in the present study, leaving open the possibility that the interaction is a scaling artifact. Other studies have reported a mix of outcomes with respect to the joint effects of divided attention and aging on recall (e.g., Light \& Prull, 1995; Park, Smith, Dudley, \& Lafronza, 1989). Without careful equating of recall in full attention study conditions, these results are difficult to evaluate. It would be possible to produce equivalent cued recall in young and old by varying the amount of study time per item or the study-to-test delays. However, the focus of the present research was on exemplar generation, and under the pres- ent experimental conditions, we did succeed in producing similar levels of priming for young and old in the full attention condition, making age comparisons of the effects of divided attention unambiguous for the indirect memory measure.

\section{EXPERIMENT 2}

The goal of Experiment 2 was to determine whether category verification behaves like category exemplar generation, demonstrating both age invariance in priming and sensitivity to divided attention. Young and older adults performed a category verification task after studying two lists of words, one under full attention and one under divided attention. As in Experiment 1, all the participants were asked to evaluate the pleasantness of words on the study lists in order to control, as best we could, the nature of processing carried out by young and older groups.

\section{Method}

Participants. Thirty-six younger adults ( 20 females and 16 males; $M$ age $=22.81$, range $=18-36$ ) and 36 older adults $(22$ females and 14 males; $M$ age $=71.67$, range $=62-80$ ), drawn from the same sources as those in the previous experiment, participated in Experiment 2 in return for a $\$ 12$ payment. The two groups did not differ in number of reported years of education $[M$ young $=16.33, M$ old $=$ $16.07 ; t(70)=0.44]$, nor did they differ in ratings of health on a $10-$ point scale $[M$ young $=8.28, M$ old $=8.06 ; t(70)=0.72]$. Young adults did score higher on the WAIS digit span forward $[M$ young $=$ $7.44, M$ old $=6.50 ; t(70)=3.04]$ and backward $[M$ young $=6.08$, $M$ old $=5.22 ; t(70)=2.57$ ] subtests. Older adults scored higher than young adults on the Nelson-Denny (1960) vocabulary measure $[M$ young $=17.31, M$ old $=21.11 ; t(70)=4.96]$, but the two groups did not differ in verbal fluency $[M$ young $=16.69, M$ old $=16.72$; $t(70)=0.02]$. Data from an additional 2 young and 8 older adults were not included in the analyses. One of the young adults was not a native speaker of English, and the other had participated in divided attention experiments in the past. Of the older adults, 3 could not perform the divided attention task, 2 were replaced because of experimenter errors, 1 was not a native speaker of English, 1 indicated that the recognition instructions were not understood, and I produced RTs in the category verification task that were more than 2.5 standard deviations from the group mean in more than half of the conditions. This latter participant was defined as an outlier and was replaced.

Materiais and Design. The study lists and experimental design for Experiment 2 were identical to those used in Experiment 1, but here we used category verification and recognition tasks, rather than category exemplar generation and cued recall tasks. Recognition was used as the direct measure of memory, rather than cued recall, because its format seems closer to that of category verification, requiring a yes/no judgment rather than response production. For the category verification task, half of the exemplars from each of the three lists ( 10 full attention, 10 divided attention, and 10 new) were presented along with their category names for category verifications. These necessitated a yes response. The category verification task also included 30 filler items, of which 14 were fillers from the study lists and 16 were new filler words not previously seen. These items were paired with experimentally generated category names to produce items necessitating no responses. This arrangement precluded effective use of an if old, then say yes strategy when making decisions about category exemplars. The fillers were not analyzed. In total, the category verification task included 60 items.

The other half of the exemplars from the three lists ( 10 full attention, 10 divided attention, and 10 new), plus 30 distractors, con- 
stituted the materials for the recognition test. The distractors were semantic associates, one for each of the categories represented in the experiment. For example, if the participants studied burglary and arson (the two exemplars used for the crime category), assault was the corresponding filler item on the recognition test. Our inclusion of semantic associates for the recognition test rendered useless a strategy by which recognition judgments could be made just by thinking of the category to which studied words belonged; the participants needed to remember the exact item that was studied, not just the categories represented on study lists, when making recognition judgments.

Procedure. The procedure for the study phase of Experiment 2 was similar to that of Experiment 1 . After both lists had been studied, the participants engaged in the letter grid task for $7 \mathrm{~min}$. For the category verification test, the participants were shown 60 test items, each item consisting of a test word with a category name below it. Each trial began with a focal cue, consisting of a small cross $(+)$ that appeared in the center of the screen for $1 \mathrm{sec}$, followed by a test word paired with a category name, also centered on the screen and separated by a single blank line (the blank line corresponded to the line on which the cross was displayed). The participants were asked to determine whether the word on top represented a member of the category name below, pressing the 1 and s keys, marked yes and no, respectively. Once a response was made, a 2 -sec blank screen followed before the focal cue for the next trial was displayed. The participants were instructed that their responses should be made as quickly and as accurately as possible once they saw the word pair on the screen. Five practice items preceded the experimental trials.

The recognition test was also computer controlled. The participants were told that they would see words, some of which had been in the two lists presented earlier. If they recognized a word as coming from any of the two study lists, they were to press the key marked yes, and if they thought that a word was new and was not presented in any of the study lists, they were to press the key marked no. Each trial consisted of a 1-sec focal cue $(+)$, which was replaced by the test word, which remained on the screen until the participant made a response, at which time it was replaced by a 2 -sec blank screen that preceded the focal cue for the next trial. No practice trials were given.

As in Experiment 1, a series of graded questions about strategies was asked after the category verification task, but before the recognition task. The questions again were designed to assess whether deliberate strategies were used during the category verification task (e.g., "While doing the task in which you made decisions about whether words belonged to certain categories, did you use information about whether the word appeared in any of the study lists to help you make a decision?"). ${ }^{3}$ Finally, demographics, digit span, vocabulary, and verbal fluency tasks were administered. The experimental session lasted about $1 \mathrm{~h}$.

\section{Results}

Divided attention. In the 40 -item divided attention block, young and older adults made similar numbers of correct responses on the odd/even judgment task $[M$ young $=38.22, M$ older $=36.94, \max$ score $=40$; $t(70)=1.66, p=.10$ ]. However, they differed significantly in the number of pleasantness responses made for study words $[M$ young $=36.89, M$ older $=32.81 ; t(70)=$ 3.22 ]. In contrast, the number of pleasantness decisions made for words presented under full attention did not vary across age, with means of 39.28 and 38.69 for young and older adults, respectively $[t(70)=1.25]$.

Category verification. The data were trimmed by eliminating trials with latencies greater than $4,000 \mathrm{msec}$ or less than $400 \mathrm{msec}$; latencies more than 2.5 standard deviations from the mean of any condition for a given participant were also removed, as were latencies for trials on which participants made errors. The percentages of trials removed for any of these reasons were 6.30 for the young and 5.00 for the old. The mean proportions of errors for the young adults were $.061, .058$, and .044 , for the full attention, divided attention, and new conditions, respectively; for the older adults, these proportions were .058 , .019 , and .019. An ANOVA produced a marginally reliable effect of age $\left[F(1,70)=3.31, M S_{\mathrm{e}}=0.008, p=.073\right]$ and a reliable effect of attention $\left[F(2,140)=4.23, M S_{\mathrm{e}}=\right.$ $0.004]$, but no interaction between these variables $[F(2,140)$ $\left.=1.68, M S_{\mathrm{e}}=0.004\right]$. Although the interaction was not reliable, the means suggest a possible difference in error rates across conditions for the old, but not for the young. In fact, separate analyses revealed no main effect of attention for the young $\left[F(2,70)=0.65, M S_{\mathrm{e}}=0.004\right]$, but an effect of attention for the old $\left[F(2,70)=6.67, M S_{\mathrm{e}}=\right.$ 0.003]. Possible implications of these differences in error rates for interpreting the latency data will be discussed below.

Mean latencies for category verification are shown in Table 2 . A 2 (age) $\times 3$ (encoding condition: full attention,

Table 2

Mean Reaction Times (in Milliseconds) on Category Verification and Proportion of Exemplars Called Old in Experiment 2 (With Standard Deviations)

\begin{tabular}{|c|c|c|c|c|c|c|c|c|c|c|c|c|}
\hline \multirow[b]{3}{*}{ Group } & \multicolumn{6}{|c|}{ Category Verification } & \multicolumn{6}{|c|}{ Recognition } \\
\hline & \multicolumn{2}{|c|}{ FA } & \multicolumn{2}{|c|}{$\mathrm{DA}$} & \multicolumn{2}{|c|}{ New } & \multicolumn{2}{|c|}{$\mathrm{FA}$} & \multicolumn{2}{|c|}{ DA } & \multicolumn{2}{|c|}{ New } \\
\hline & $M$ & $S D$ & $M$ & $S D$ & $M$ & $\overline{S D}$ & $M$ & $\overline{S D}$ & $M$ & $S D$ & $M$ & $S D$ \\
\hline \multicolumn{13}{|c|}{ All Participants } \\
\hline Young & 945 & 193 & 945 & 194 & 1,012 & 228 & .933 & .107 & .758 & .146 & .072 & .097 \\
\hline Older & 1,186 & 209 & 1,198 & 255 & 1,194 & 221 & .864 & .125 & .561 & .232 & .092 & .127 \\
\hline Mean & 1,065 & & 1,071 & & 1,103 & & .899 & & .660 & & .082 & \\
\hline \multicolumn{13}{|c|}{ Matched Subgroups } \\
\hline Young & 959 & 195 & 953 & 195 & 1,025 & 233 & .937 & .110 & .750 & .146 & .080 & .103 \\
\hline Older & 1,187 & 217 & 1,187 & 250 & 1,182 & 228 & .880 & .103 & .600 & .229 & .093 & .131 \\
\hline Mean & 1,073 & & 1,070 & & 1,104 & & .908 & & .675 & & .087 & \\
\hline
\end{tabular}

Note-FA, full attention; DA, divided attention. 
divided attention, new) ANOVA, with repeated measures on the last factor, was used to analyze the data. Older adults were slower overall $(1,193 \mathrm{msec})$ than young adults $(967 \mathrm{msec})$ in making semantic judgments $[F(1,70)=$ $\left.21.65, M S_{\mathrm{e}}=126,930\right]$. There was also a main effect of condition, in that some conditions produced faster latencies than others $\left[F(2,140)=3.78, M S_{\mathrm{e}}=7,797\right]$. However, there was also a significant interaction between age and condition $\left[F(2,140)=3.34, M S_{\mathrm{e}}=7,797\right]$.

An inspection of the verification means in Table 2 suggests that priming was obtained for full and divided attention conditions for young adults but that no priming occurred for either condition in older adults. These visual impressions were borne out by further analyses contrasting the full and divided attention conditions with the new condition. Although words studied under full attention were verified faster $(1,065 \mathrm{msec})$ than new words $\left[1,103 \mathrm{msec} ; F(1,70)=6.34, M S_{\mathrm{e}}=8,083\right]$, this difference was not consistent across age $\left[F(1,70)=3.91, M S_{\mathrm{e}}=\right.$ $8,083, p=.052]$. Similarly, divided attention words produced faster RTs $(1,071 \mathrm{msec})$ than did new words $\left[F(1,70)=4.27, M S_{\mathrm{e}}=8,390\right]$, but again there was an interaction involving age $\left[F(1,70)=5.40, M S_{\mathrm{e}}=8,390\right]$. The difference between full and divided attention words, however, was not significant $\left[F(1,70)=0.20, M S_{\mathrm{e}}=\right.$ $6,916]$, nor was the interaction involving age $[F(1,70)=$ $\left.0.18, M S_{\mathrm{e}}=6,916\right]$.

To further explore the nature of the age $\times$ attention interaction, we performed separate analyses of young and older adults. A one-way repeated measures ANOVA restricted to young adults revealed a main effect of study condition $\left[F(2,70)=7.40, M S_{\mathrm{e}}=7,322\right]$. Latencies for full attention words were significantly faster than new word latencies $\left[F(1,35)=10.85, M S_{\mathrm{e}}=7,528\right]$, as were divided attention latencies $\left[F(1,35)=9.22, M S_{\mathrm{e}}=8,766\right]$. The difference between full and divided attention latencies for the young was not reliable $\left[F(1,35)=0.00, M S_{\mathrm{e}}=\right.$ $5,672]$. When we analyzed the older adults' data, however, a different pattern emerged. The main effect of attention was not significant $\left[F(2,70)=0.16, M S_{\mathrm{e}}=8,271\right]$, nor were any of the contrasts (all $F_{\mathrm{S}}<1$ ).

To equate young and older adults on performance on the divided attention tasks during the study phase of the experiment, we reanalyzed the data after excluding the 6 young adults who scored highest on number of pleasant judgments and the 6 older adults who made the least number of such judgments. The remaining 30 participants in each age group were well matched on accuracy on the addition task $[M$ young $=38.00, M$ old $=37.80$; $t(58)=0.28]$ and on number of pleasantness judgments $[M$ young $=36.27, M$ old $=35.07 ; t(58)=1.39]$. As is evident in Table 2, the patterns of results for the matched subgroups and for the full samples were quite similar. This conclusion is confirmed by the ANOVA. Although the main effect of study conditions was only marginally significant in this analysis, presumably due to reduced power, the remaining effects were as reported above.
Recognition. Mean proportions of items designated as old in the recognition test are also represented in Table 2. Such responses are hits for the full attention and divided attention conditions, but they are false alarms for new words. A 2 (age) $\times 3$ (encoding condition) ANOVA revealed main effects of both age $\left[F(1,70)=14.33, M S_{\mathrm{e}}=\right.$ $0.026]$ and encoding condition $\left[F(2,140)=661.93, M S_{\mathrm{e}}=\right.$ $0.019]$, as well as an interaction between these variables $\left[F(2,140)=11.13, M S_{\mathrm{e}}=0.019\right]$. To examine the data more closely, we first compared false alarm rates across the two groups; the difference was not significant $[F(1,70)$ $\left.=0.53, M S_{\mathrm{e}}=0.013\right]$. Following this, we analyzed the hit rate data with a 2 (age) $\times 2$ (attention condition: divided attention, full attention) ANOVA, again with repeated measures on the last factor. Young adults made more hits overall (.846) than did older adults [.713; $\left.F(1,70)=19.25, M S_{\mathrm{e}}=0.033\right]$, and full attention words produced more hits overall (.899) than did divided attention words $\left[.660 ; F(1,70)=115.18, M S_{\mathrm{e}}=0.018\right]$. However, there was also a significant interaction between age and encoding condition $\left[F(1,70)=8.24, M S_{\mathrm{e}}=0.018\right]$. Inspection of the means in Table 2 indicates that the age difference in hit rates was greater in the divided attention condition than in the full attention condition. However, the age difference in hit rates was significant for both full attention $\left[F(1,70)=6.44, M S_{\mathrm{e}}=0.013\right]$ and divided attention $\left[F(1,70)=18.61, M S_{\mathrm{e}}=0.038\right]$.

We also analyzed the recognition data for the 30 young and 30 older adults in the matched subgroups. As is evident in Table 2, the means for the subgroups closely resemble those for the full samples. It is no surprise, then, that conclusions based on the subgroups are the same as those based on the full samples.

\section{Discussion}

There are two noteworthy findings in Experiment 2. First, divided attention reduced hit rates in recognition for both young and older adults. Thus, dividing attention clearly affected adequacy of processing during study. Moreover, the effect of dividing attention on recognition accuracy was disproportionately greater for older adults. As in Experiment 1, however, young and older adults differed in accuracy in the full attention as well as in the divided attention condition, leaving open the possibility of a scaling artifact. In some studies in which young and old have similar recognition performance in full attention, there have been no interactions between age and encoding condition (Light \& Prull, 1995, Experiment 2; Park, Puglisi, \& Smith, 1986; Park, Puglisi, Smith, \& Dudley, 1987). The present results, then, should be interpreted cautiously.

Second, the attention manipulation did not affect priming in the category verification task. Moreover, the absence of a divided attention effect in category verification was obtained only for young adults. Older adults showed no priming in category verification here. Note that older adults made more errors in the full attention condition 
than in the remaining conditions, so that, if anything, we might have expected faster latencies in this condition if there were a speed-accuracy tradeoff for these participants, but this did not occur. The absence of priming in older adults is unusual (La Voie \& Light, 1994). Thus, before concluding that there are age deficits in category verification, we replicated Experiment 2 with a slightly different version of the test procedure.

\section{EXPERIMENT 3}

RTs in Experiment 2 were fairly long, with means of $967 \mathrm{msec}$ for young adults and $1,193 \mathrm{msec}$ for older adults. A concern is that these long RTs are due in part to variability in maintaining task set when two words are presented simultaneously. In Experiment 3, we instituted a procedural change designed to eliminate this problem. Instead of the names of category and instance appearing on the monitor simultaneously, the name of the category appeared for $1 \mathrm{sec}$ before being joined by the name of the instance for a decision about category membership. This revised procedure (suggested by John Gabrieli) has the advantage of guaranteeing that category names will be processed prior to instances. This change was also expected to reduce RTs by eliminating reading time for the category name from the decision latencies. In addition, instead of presenting two lists for study and then administering the category verification test, we gave the participants two study-test blocks, with one list studied under full attention and one under divided attention. We also eliminated the 7-min filler task used in Experiment 2 to separate study and test. The effects of study-test delay on priming in category verification are unknown. It is conceivable that priming in category verification is relatively short-lived, reducing its sensitivity to effects of variables such as age and divided attention.

\section{Method}

Participants. Twenty-four young adults ( 16 females and 8 males; $M$ age $=19.42$, range $=17-30)$ and 24 locally residing older adults ( 16 females and 8 males; $M$ age $=73.42$, range $=62-81$ ) participated in this study in exchange for a $\$ 12$ payment. The older adults reported having more years of education than the young adults $[M$ young $=14.06, M$ old $=17.85 ; t(46)=4.29]$. The two groups were similar with respect to self-ratings of health $[M$ young $=7.08$, $M$ old $=7.83 ; t(46)=1.42]$. They did not differ in WAIS digit span forward $[M$ young $=6.83, M$ old $=6.79 ; t(46)=0.10]$, but they did differ in backward span $[M$ young $=6.04, M$ old $=5.42 ; t(46)=$ $2.02]$. Older adults scored higher on our 25 -question version of the Nelson-Denny (1960) vocabulary test $[M$ young $=14.17, M$ old $=$ $21.71 ; t(46)=8.71]$, but not on our measure of verbal fluency $[M$ young $=15.83, M$ old $=15.25 ; t(45)=0.37]$. (The $d f$ for verbal fluency reflect the loss of data for 1 young participant owing to experimenter error.) For purposes unrelated to the present discussion, the participants were tested on a locally developed letter cancellation task to obtain a measure of perceptual-motor speed. Two forms of the test were administered, with scores (number of letters correctly cancelled) averaged across the two forms. As is generally the case, young adults outperformed older adults, with means of 16.48 and $11.41[t(45)=4.18]$. (Data were not available on the speed measure for 1 older adult.)
Data from an additional 8 young and 7 older adults were discarded from the following analyses. Of the young adults, 3 were non-native speakers of English, 3 produced latencies greater than 2.5 standard deviations from group means in $50 \%$ or more of the experimental conditions (these were defined as outliers and were replaced), 1 made no pleasantness judgments during full attention study (see below) and may have misunderstood the instructions, and 1 was replaced because of an experimenter error. Of the older adults, 5 produced fewer than our criterion of 24 responses on the primary number addition task during divided attention, 1 did not perform the secondary task of making pleasantness ratings during divided attention, and data from 1 older adult were discarded owing to a computer malfunction that occurred during testing.

Materials and Design. Four lists of 18 exemplars were created by picking 2 exemplars from each of nine different categories in the Battig and Montague (1969) norms; thus, we had 72 critical items altogether. Categories and their corresponding exemplars were, with a few exceptions, drawn from the earlier studies reported here. Exemplars were assigned to lists, with the restriction that there were no closely related categories within a list (i.e., clothing and footwear). The lists were similar in frequency in the English language, using the Francis and Kučera (1982) norms $(M=11.00$, range $=0-91)$, rank in the Battig and Montague norms $(M=10.45$, range $=5-26)$, number of letters $(M=6.14$, range $=3-9)$, and number of syllables $(M=2.06$, range $=1-4)$. To each of these four target lists of 18 items, we added a different list of 18 filler nouns. The filler lists had frequency, letter, and syllable counts similar to those of the target lists and contained no categories represented by the critical exemplars. Thus we had four lists of 36 words each; half of the words on each list were target exemplars, and half were fillers. Lists were rotated through the four encoding conditions (full attention study, full attention baseline, divided attention study, and divided attention baseline). Across participants, each list was represented in each condition equally often.

The design was a 2 (age) $\times 2$ (encoding: full, divided) $\times 2$ (test status: old, new) $\times 2$ (study order: DA study and test followed by FA study and test, FA study and test followed by DA study and test) mixed factorial, in which the first and last factors were manipulated between participants, and the second and third factors were manipulated within participants.

Procedure. After informed consent was given, the participants performed a speeded letter identification task. They were given three sheets of paper, each consisting of a randomly generated grid of letters, and had 1 min to scan the sheets and circle as many $A \mathrm{~s}$ as they could. Following the initial perceptual speed test, the participants were given 40 trials on the number addition practice task. This practice task was then followed by the first study-test block, in which the study portion was either full or divided attention. For full attention, the participants were shown a list of 36 words presented for $3 \mathrm{sec}$ each with intentional encoding instructions. Pleasantness responses were made while each word remained on the screen; the / key, labeled pleasant, was pressed if the participants found the meaning of the word pleasant, and the $z$ key was pressed if they found the meaning of the word unpleasant. For divided attention, a new list of 36 words was presented, again with intentional encoding instructions. As in Experiments 1 and 2, the participants made pleasantness decisions using the keys on the keyboard, and reported aloud whether the sum of the flanking numbers was even or odd. A 20 -word divided attention practice block preceded the experimental divided attention study block.

A category verification task occurred immediately after each of the two study lists, so that all the participants completed two study-test blocks. Each category verification block consisted of 72 trials. On each trial, a cross hair focal cue was presented in the middle of the screen for $1 \mathrm{sec}$, followed by the name of the category alone, presented to the left of the focal cue for $1 \mathrm{sec}$, after which it was joined by the test word, which could be either old or new. The 
test word was presented to the right of the category name, and both items remained on the screen until a response was made. If the test word was a member of the category named (e.g., weapon cannon), the L key (labeled yes) was pressed. If not (e.g., music shower), the $\mathrm{S}$ key (labeled no) was pressed. Both category name and test word remained on the screen until a response was made, after which a blank screen was presented for $2 \mathrm{sec}$, followed by the focal cue for the next trial. For each test block, 5 practice trials preceded the initiation of the 72 experimental trials. These practice trials were fillers and involved different words and categories in the two test blocks.

The category verification task included 18 old and 18 new target words, as well as 18 old and 18 new filler words. All the target items were presented with their superordinate category name, regardless of whether they were old or new, and therefore they all required a yes response. All filler items, regardless of their study status, were presented with category names used for the target items. Because the filler items belonged to none of the target categories, the filler items all required no responses. We thus had, for each of the two category verification test blocks, an equal number of old and new target and filler items.

To assess use of deliberate recollection, we administered the strategy questionnaire after the second category verification task. ${ }^{4}$ We then tested recognition for all the target words presented in the study lists. Eighteen full attention and 18 divided attention words were presented in four columns intermixed with 36 new distractors, for a 72-item test. The distractors were words chosen from each of the categories represented by all of the studied words on the test. For example, if cannon and spear were studied, which were members of the weapon category, pistol would be the distractor. The participants were asked to think back to the lists they studied earlier and to circle words they remembered as having been studied. They were given an unlimited amount of time to complete this test.

The experimental session ended with administration of a second version of the letter cancellation task, using three new letter grid sheets, the forward and backward versions of the WAIS digit span test, the verbal fluency measure, and our 25-item version of the Nelson-Denny (1960) vocabulary test. The experimental session lasted about $1 \mathrm{~h}$. The participants were paid $\$ 12$.

\section{Results}

Divided attention. In the divided attention block, young and older adults differed in the number of correct responses made in the odd/even judgment task $[M$ young $=34.58$, $M$ old $=32.38 ; t(46)=2.61]$ and in the number of pleasantness ratings given to words studied under divided attention [ $M$ young $=33.04, M$ old $=28.21 ; t(46)=2.93$ ] In contrast, there was little difference between young and older adults on the number of pleasantness ratings made for words under full attention, with young adults having a mean of 35.38 responses and older adults having a mean of 35.04 responses $[t(46)=0.65]$.

Category verification. Before analyzing the RT data, we cleaned the data. First, we eliminated from analysis any experimental trial that produced a wrong response. This process removed $4.80 \%$ and $2.20 \%$ of the young and older adults' data, respectively. Second, we eliminated trials with RTs of less than $400 \mathrm{msec}$ or more than $4,000 \mathrm{msec}$ and trials with RTs that deviated more than 2.5 standard deviations from a given condition mean. This second cleaning process removed an additional $4.17 \%$ of the young adults' data and $2.31 \%$ of the older adults' data.

We examined error rates in category verification to explore the possibility of a speed-accuracy tradeoff. The
Table 3

Mean Reaction Times (in Milliseconds; With Standard Deviations) on the Category Verification Task in Experiment 3

\begin{tabular}{|c|c|c|c|c|c|c|c|c|}
\hline \multirow[b]{3}{*}{ Group } & \multicolumn{4}{|c|}{ Full Attention } & \multicolumn{4}{|c|}{ Divided Attention } \\
\hline & \multicolumn{2}{|c|}{ Studied } & \multicolumn{2}{|c|}{ New } & \multicolumn{2}{|c|}{ Studied } & \multicolumn{2}{|c|}{ New } \\
\hline & $M$ & $S D$ & $M$ & $S D$ & $M$ & $S D$ & $M$ & $S D$ \\
\hline \multicolumn{9}{|c|}{ All Participants } \\
\hline Young & 743 & 152 & 801 & 168 & 726 & 140 & 773 & 140 \\
\hline Older & 770 & 138 & 815 & 169 & 767 & 111 & 789 & 118 \\
\hline Mean & 757 & & 808 & & 746 & & 781 & \\
\hline \multicolumn{9}{|c|}{ Matched Subgroups } \\
\hline Young & 743 & 161 & 801 & 179 & 729 & 146 & 765 & 136 \\
\hline Older & 749 & 139 & 794 & 160 & 752 & 112 & 764 & 111 \\
\hline Mean & 746 & & 797 & & 741 & & 765 & \\
\hline
\end{tabular}

mean percentages of errors for the young adults were $6.02,5.09,3.70$, and 4.40 for the full attention studied items, full attention new items, divided attention studied items, and divided attention new items, respectively; for older adults, the corresponding percentages were 2.55 , $2.32,2.55$, and 1.39. A 2 (age) $\times 2$ (encoding: full, divided) $\times 2$ (test status: old, new) ANOVA revealed only a main effect of age. Older adults made fewer errors overall $(2.20 \%)$ than did young adults $[4.80 \% ; F(1,46)=$ $10.45, M S_{\mathrm{e}}=0.003$ ], suggesting that they were more cautious than the young in making semantic judgments. However, the error means are very similar across conditions within age groups, so there is little concern about speed-accuracy tradeoffs here.

Mean latencies for category verification are displayed in Table 3. A 2 (age) $\times 2$ (encoding: full, divided) $\times 2$ (test status: old, new) ANOVA was conducted, with repeated measures on the last two factors. Older adults had slightly longer category verification latencies than did young adults, but the difference between groups was not reliable $\left[F(1,46)=0.42, M S_{\mathrm{e}}=69,664\right]$. (Although this is somewhat surprising in view of the age difference in the letter cancellation task, absence of age differences in latencies for baseline (unstudied) items simplifies interpretation of priming effects.) Nor was there a main effect of encoding condition $\left[F(1,46)=2.64, M S_{\mathrm{e}}=6,408\right]$. As was expected, studied exemplars were judged faster $(M=752 \mathrm{msec})$ than new exemplars $[M=795 \mathrm{msec}$; $\left.F(1,46)=28.82, M S_{\mathrm{e}}=3,059\right]$. This effect was similar across age, since there was no interaction between test status and age $\left[F(1,46)=1.45, M S_{\mathrm{e}}=3,059\right]$. In addition, the facilitation produced by study was not affected by attention, because test status did not interact with encoding $\left[F(1,46)=1.08, M S_{\mathrm{e}}=3,134\right]$. The three-way interaction between encoding, study status, and age group was nonsignificant $\left[F(1,46)=0.13, M S_{\mathrm{e}}=3,134\right]$. Neither aging, nor divided attention, nor their combination affected the degree of priming in category verification.

It was possible to match young and older adults for performance in the divided attention tasks by eliminating data from 4 people in each age group. In the matched subgroups, young and older adults were similar in accu- 
Table 4

Mean Proportion (With Standard Deviations) of Exemplars Called Old in Recognition in Experiment 3

\begin{tabular}{|c|c|c|c|c|c|c|}
\hline \multirow[b]{2}{*}{ Group } & \multicolumn{2}{|c|}{ Full Attention } & \multicolumn{2}{|c|}{ Divided Attention } & \multicolumn{2}{|c|}{ New } \\
\hline & $M$ & $S D$ & $\underline{M}$ & $S D$ & $M$ & $S D$ \\
\hline \multicolumn{7}{|c|}{ All Participants } \\
\hline Young & .912 & .153 & .853 & .209 & .041 & .048 \\
\hline Older & .922 & .119 & .891 & .131 & .086 & .103 \\
\hline Mean & .917 & & .872 & & .063 & \\
\hline \multicolumn{7}{|c|}{ Matched Subgroups } \\
\hline Young & .925 & .112 & .851 & .208 & .044 & .051 \\
\hline Older & .926 & .125 & .914 & .115 & .092 & .112 \\
\hline Mean & .926 & & .883 & & .068 & \\
\hline
\end{tabular}

racy on the addition task $[M$ young $=34.40, M$ old $=$ $33.45 ; t(38)=1.23$ ] as well as in number of pleasantness judgments made during study $[M$ young $=32.45, M$ old $=$ $30.90 ; t(38)=1.51]$. Mean category verification latencies for the matched subgroups (see Table 3 ) closely resemble those for the full samples. An ANOVA produced the same pattern of significant and nonsignificant effects as that seen in the full samples.

Recognition. Mean proportions of items designated as old on the recognition test are given in Table 4. For the full attention and divided attention conditions, these responses are hits; for new items, they are false alarms. A 2 (age) $\times 3$ (encoding condition) ANOVA produced neither a reliable main effect of age nor a reliable interaction between age and encoding condition $[F(1,46)=$ $1.22, M S_{\mathrm{e}}=0.029$, and $F(2,92)=0.30, M S_{\mathrm{e}}=0.013$, respectively]. The effect of encoding condition was reliable $\left[F(2,92)=828.43, M S_{\mathrm{e}}=0.013\right]$. Items studied under full attention were recognized marginally better than items studied under divided attention $[F(1,46)=$ 3.73, $M S_{\mathrm{e}}=0.013, p<.06$ ], as in Experiment 2. Both items studied under full attention and those studied under divided attention were discriminated reliably from new items $\left[F(1,46)=1,581.39, M S_{\mathrm{e}}=0.011\right.$, and $F(1,46)=$ $983.44, M S_{e}=0.016$, respectively]. For the matched subsamples, the pattern of means and of significant and nonsignificant effects closely resembles that of the full samples (see Table 4), although with the reduced numbers of participants, the difference between full and divided attention was clearly not reliable $(p>.10)$.

\section{Discussion}

The changes we made in the category verification procedure had the desired effect of reducing RTs. With the study-test procedure used here, the age difference in priming observed in Experiment 2 was no longer evident. However, the absence of attentional effects reported for Experiment 2 was replicated here regardless of whether the full sample or the matched sample was considered. Despite our failure to obtain an effect of divided attention on priming in category verification, we did observe one in recognition memory, indicating that the number addition task was sufficiently difficult to disrupt the encoding required to sustain recognition performance. The magnitude of the divided attention effect in recognition did not interact with age, presumably because hit rates were near ceiling owing to the very brief study-test interval and the fact that, in this experiment, all of the old words on the recognition test had been presented for both study and category verification.

\section{EXPERIMENT 4}

Experiments 2 and 3 produced null effects of divided attention on priming in category verification. Because we began with the assumptions that category verification is a conceptually driven task and that priming on conceptually driven tasks is influenced by semantic processing during study, these findings were unanticipated. Deciding that a word is an instance of a particular category requires access to meaning and thus must be conceptually driven, in this sense. However, as was noted earlier, the category verification task, in our work, was visual, so that category exemplars were presented in the same modality at study and test. A hallmark of conceptually driven tasks is that they are insensitive to the influence of modality shifts between study and test, whereas perceptually driven tasks are sensitive to such shifts (Srinivas \& Roediger, 1990). Although category verification requires semantic access, the locus of priming in this task could be perceptual - that is, dependent on similarity in presentation format at study and test. In Experiment 4, we examined the question of whether conceptual priming would be better for words presented in the same modality at study and test than for words presented in different modalities. The participants studied two lists of words and received a visual category verification test after each. For one list, the participants judged the pleasantness of each word, and for the other they counted the number of syllables in each. On each list, half of the words were presented visually, and half were presented auditorily.

\section{Method}

Participants. Thirty-two young adults (18 females and 14 males) drawn from the student population of the Claremont Colleges $(M=$ 20.09, range $=18-34$ ) participated in Experiment 4 in return for a $\$ 12$ payment. They had a mean of 14.31 years of education (range $=$ 12-17) and generally reported themselves to be in good health $(M=$ 7.53 , range $=2-10$ ). They scored means of 7.13 on the WAIS forward digit span subtest (range $=5-9$ ) and 5.94 on the backward subtest (range $=4-8$ ). Finally, they scored a mean of 16.16 correct responses on our 25-item version of the Nelson-Denny (1960) vocabulary test (range $=10-24$ ) and produced a mean of 16.16 words beginning with the letter $F$ on our fluency test (range $=7-24$ ). These 32 participants all denied using strategies involving deliberate recollection of studied words on the category verification task. An additional 9 participants claimed to be guessers. In Experiments 1-3, we conducted analyses for all the participants and for just those participants who claimed not to have guessed. This approach to data analysis has the disadvantage that participants may be lost differentially from the various cells in the design, so that an experiment 
that is designed to be fully counterbalanced no longer is. In this experiment, we replaced those participants who claimed to have guessed. We report analyses only for the 32 nonguessers; analyses including both guessers and nonguessers combined led to the same conclusions. The data from an additional 4 people were discarded. One person used the wrong keys to respond on the category verification task, 1 had been tested in a similar study previously, 1 exceeded our age criterion for the younger sample, and 1 had latencies more than 2.5 standard deviations from the mean of the entire sample on half of the experimental conditions (and hence was an outlier).

Design and Materials. The design of the experiment was 2 (encoding task: syllable counting vs. pleasantness rating) $\times 2$ (test status: studied vs. new) $\times 2$ (study modality: visual vs. auditory) $\times 2$ (study order: syllable counting first vs. pleasantness rating first).

Four lists of 36 words each ( 18 exemplars and 18 fillers) were used. These were identical to those used in Experiment 3, with the exception of three new exemplars that were substituted for words that were homonyms (e.g., birch was substituted for fir). The four lists were used equally often across the 32 nonguessing participants in the four encoding conditions (syllable counting studied, syllable counting new, pleasantness judgment studied, pleasantness judgment new). At study, half of the words of each list were presented auditorily, and half were presented visually. Within a study list, words were intermixed, with the constraint that no more than 3 consecutive words were presented in the same modality. For auditory presentation, words were recorded in a male voice, using Sound Blaster Pro. One exemplar from each of the experimental categories was presented auditorily, and one was presented visually.

Procedure. As in Experiment 3, the participants first engaged in a perceptual speed task. This was followed by two blocks of study and test trials. For the syllable-counting block, the participant counted the number of syllables in each word and responded orally. For the pleasantness-rating task, the participants gave an oral rating on a 5 -point scale $(1=$ very unpleasant, $5=$ very pleasant $)$. Each block of 36 study words was preceded by a 6 -item practice list. Presentation rate was $3 \mathrm{sec}$ per item. The mean pronunciation time was $782 \mathrm{msec}$ per word; for auditorily presented items, the remainder of the 3-sec presentation time was silent. Visually presented words appeared on the monitor for $1,500 \mathrm{msec}$, followed by a blank screen for $1,500 \mathrm{msec}$. Immediately following each of the two study lists, the participants performed a 5-item practice block on the category verification task followed by the 72 -item experimental block. The procedure for this task was identical to that of Experiment 3. The experimental session continued with administration of the strategy questionnaire, followed by a second measure of perceptual speed, the digit span task, the verbal fluency test, and our 25 -item version of the Nelson-Denny (1960) vocabulary test. The session lasted about $1 \mathrm{~h}$.

\section{Results}

Prior to examination of latencies, trials on which the participants made errors were eliminated; this procedure accounted for a loss of $5.12 \%$ of the data. Next, trials on which RTs were shorter than $400 \mathrm{msec}$ or longer than $4,000 \mathrm{msec}$ were removed; finally, trials with response latencies more than 2.5 standard deviations from each

Table 5

Mean Reaction Times (in Milliseconds; With Standard Deviations) on the Category Verification Task in Experiment 4

\begin{tabular}{|c|c|c|c|c|c|c|}
\hline \multirow[b]{2}{*}{ Task } & \multicolumn{2}{|c|}{ Auditory } & \multicolumn{2}{|c|}{ Visual } & \multicolumn{2}{|c|}{ New } \\
\hline & $M$ & $S D$ & $M$ & $S D$ & $M$ & $S D$ \\
\hline Syllable counting & 822 & 159 & 812 & 187 & 844 & 176 \\
\hline Pleasantness judgme & 806 & 179 & 813 & 162 & 838 & 180 \\
\hline Mean & 814 & & 813 & & 841 & \\
\hline
\end{tabular}

participant's mean in a particular condition were discarded. An additional $2.00 \%$ of the data were lost as a result of the latter two procedures. Error rates in the syllable-counting condition were $2.8 \%$ for items presented auditorily, $5.9 \%$ for items presented visually, and $4.3 \%$ for new items; in the pleasantness-rating condition, error rates were $4.9 \%, 6.6 \%$, and $6.3 \%$ for auditory, visual, and new items, respectively. Error rates were analyzed in a 2 (orienting task) $\times 3$ (test status: auditory vs. visual vs. new) ANOVA. Somewhat fewer errors were made following encoding in the syllable-counting condition (4.3\%) than in the pleasantness-rating condition $[5.9 \% ; F(1,31)=$ $\left.2.96, M S_{\mathrm{e}}=0.004, p=.10\right]$.

Mean response latencies are given in Table 5. An inspection of the means suggests that category verification of previously studied words was carried out more rapidly than category verification involving new words but that priming varied with neither input modality nor encoding task. The results of a 2 (orienting task) $\times 3$ (test status) ANOVA confirmed these impressions. There was a main effect of test status $\left[F(2,62)=3.69, M S_{\mathrm{e}}=4,288.98\right]$, but neither the main effect of orienting task nor the interaction of orienting task with test status was reliable (both $F \mathrm{~s}<1$ ). Follow-up comparisons indicated that the 1msec difference between auditory and visual study conditions was not reliable $(F<1)$ and that the means of both auditory $(814 \mathrm{msec})$ and visual $(813 \mathrm{msec})$ conditions were lower than that of new items $[841 \mathrm{msec} ; F(1,31)=$ $4.64, M S_{\mathrm{e}}=4,793.55$, for the auditory condition, and $F(1,31)=7.38, M S_{\mathrm{e}}=3,412.88$, for the visual condition].

\section{Discussion}

The results of Experiment 4 are unambiguous. Priming was obtained in the category verification task using the procedures of Experiment 3, but there was no indication that such priming was enhanced either by semantic processing during study or by a match between presentation modalities at study and test. Thus, Experiments $2-4$ collectively demonstrate that priming in category verification is insensitive to level of processing at study and to the presence of a demanding distraction task at study.

\section{GENERAL DISCUSSION}

The principal findings of our research can be summarized as follows. (1) In each experiment in which deliberate recollection was indexed by cued recall or by recognition (i.e., in Experiments 1, 2, and 3), division of attention impaired performance. These results are not newsworthy (and we do not dwell on them further), but recapitulating them here establishes our ability to replicate standard findings in the literature. (2) The manipulation of attention at study that moderated priming in exemplar generation failed to do so in category verification. (3) Although young adults outperformed older adults on cued recall (Experiment 1) and recognition (Experiment 2, although not Experiment 3, where there were ceiling effects), age differences were not found in exemplar gen- 
eration. Although older adults exhibited no priming in category verification in Experiment 2, whereas young adults did, age differences in priming on this task were not reliable in Experiment 3. Attention did not interact with age for either conceptual-priming task. We now explore the implications of the latter two points.

\section{Conceptual Priming}

Conceptual-priming tasks are generally thought to be those that require access to semantic information at test (e.g., Schacter, Chiu, \& Ochsner, 1993; Vaidya et al., 1997; Vriezen et al., 1995). When proponents of transferappropriate processing offer, as part of the operational definition of conceptual tasks, the criterion that they be sensitive to level of processing at encoding, with semantic processing or generation from definitions producing more priming, this is no doubt what they have in mind (e.g., Blaxton, 1989; Roediger \& McDermott, 1993). By this logic, dividing attention should limit semantic processing during encoding and should have deleterious effects on conceptual priming. Indeed, that is what we have found for exemplar generation, and what has been found by previous investigators of this task who have varied level of encoding or who have used sufficiently demanding distractor activities during encoding (e.g., Gabrieli et al., 1995; Hamann, 1990; Maki \& Knopman, 1996; Monti et al., 1996; Mulligan, 1997; Mulligan \& Hartman, 1996). By contrast, in the present experiments, neither reduced level of processing nor division of attention has produced reliable deficits in priming in category verification. Category verification thus appears to fit our intuitive notions of a conceptually driven priming task, but not the operational definition of such tasks.

Before discussing the theoretical ramifications of these findings, we need to rule out two alternative accounts of our category verification data. First, as was noted earlier, classification tasks can be quite sensitive to the match between encoding and test tasks even within the semantic domain (Vriezen et al., 1995). Hence, it is possible that our failure to observe effects of encoding task on category verification in Experiment 4 and our failure to observe divided attention effects in Experiments 2 and 3 are due to lack of compatibility between the encoding required by the category verification task and the encoding carried out during study. A similar account could be given for Vaidya et al.'s (1997) failure to find an effect of level of processing on category verification following a study task in which participants decided whether each word named something that was man-made. This seems unlikely, inasmuch as the same encoding tasks used in our category verification studies (with the exception of Experiment 4 , in which the nonsemantic task was syllable counting rather than vowel counting) were also used in our category exemplar generation study and exemplar generation is known to be sensitive to the congruency between study and test tasks within the semantic domain (Cabeza, 1994). Deciding whether a word belongs to a particular category and generating it from a category name would seem a priori to involve access to the same domains of information at test. It would therefore be reasonable to expect similar effects of encoding tasks on priming in these paradigms. Moreover, Vaidya et al. observed no advantage in priming for deep processing over shallow processing in an abstract/concrete classification task in which the deep task was identical at study and test. Conversely, Gabrieli et al. (1999) found no effect of divided attention on priming in category verification when study and test classification tasks differed. Priming in category verification appears to be immune to the effects of divided attention both when the study and test tasks require the same judgment and when they do not. Thus, our effects (or noneffects) are probably not due to an infelicitous choice of encoding tasks.

Second, whenever divided attention fails to impair performance, there is always a risk that the task used to divide attention is not difficult enough (Mulligan, 1997, 1998; Mulligan \& Hornstein, 2000). The internal evidence here argues against this. Performance on the number addition task was not perfect for either young or older adults under divided attention conditions, suggesting that effort was required. Also, doing the divided attention task was sufficient to produce decrements in cued recall, recognition, and exemplar generation priming. Similarly, Gabrieli et al. (1999) reported that keeping track of sequences of three consecutive odd numbers reduced priming in exemplar generation, but not in category verification. Nonetheless, Mulligan (1997, 1998; Mulligan \& Hornstein, 2000) has shown that varying the difficulty of concurrent activities affects the magnitude of priming for some tasks, but not for others. Without systematic manipulation of the attentional requirements of distractor tasks, we cannot conclude with certainty that priming in semantic verification tasks is immune from the effects of divided attention. What we can say is that under study conditions that affect priming in exemplar generation, category verification has now proven resistant to divided attention effects in two independent investigations, ours and that of Gabrieli et al. (1999).

We turn now to the major question raised by our findings-namely, enunciation of the conditions under which divided attention can be expected to affect priming in indirect memory tasks. Our results raise problems for hypotheses that divided attention will reduce priming in conceptual indirect memory tests if such tests are defined intuitively in terms of the requirement that semantic information be accessed for their successful performance. Both exemplar generation and category verification require access to semantic information, but only the former is susceptible to either levels-of-processing or divided attention effects. If, on the other hand, we predict that only tasks that meet the criteria suggested by Srinivas and Roediger (1990) for conceptual-priming tests will show effects of divided attention, the situation does not improve. Although priming in category verification did not vary with levels of processing (Experiments 2 and 3 ), it was also unaffected by a change in modality between 
study and test (Experiment 4). Thus, category verification cannot be exempted from the prediction that priming should be disrupted by reduced attention on the grounds that it is a perceptually driven task-it does not meet Srinivas and Roediger's criteria for such tasks either. Moreover, some tasks, such as word-stem completion and naming, that generally are not sensitive to levels-of-processing effects (see Brown \& Mitchell, 1994, for a different view) but are sensitive to modality shifts between study and test have shown divided attention effects, whereas others, such as lexical decision and word-fragment completion, have not.

Gabrieli and his colleagues (e.g., Fleischman \& Gabrieli, 1998; see Vaidya et al., 1997, for a similar argument with respect to levels of processing) have hypothesized that divided attention will reduce priming in tasks for which there are multiple possibilities for correct responding at test, but not for tasks on which only a single correct response is possible for each test item. This classificatory scheme handles the discrepancy in findings between word-stem completion (multiple correct responses are possible) and word-fragment completion (usually only one response is correct) and between exemplar generation (multiple correct responses) and category verification (one correct response), without invoking the distinction between perceptual and conceptual processing. Memory search is said to be convergent when there is a single correct response but divergent when there are many. However, this account founders on Light and Prull's (1995) observation of divided attention effects in word naming. Moreover, priming in tasks that appear to have a single correct solution, such as perceptual identification of words and word-fragment completion, may in fact be subject to competition from words similar to the correct solution (Ratcliff \& McKoon, 1996, 1997; Smith \& Tindell, 1997); thus, these tasks may also require selection of one response from several activated representations. Finally, in the category verification task used in Experiment 3 and that used by Gabrieli et al. (1999), the category name appeared prior to the instance to be verified. Because instances were chosen to be among the less frequent associates to category names, it is possible that category members other than the target could have been activated; thus, it is not obvious to us that category verification, despite the fact that there is a single correct response to each item, does not permit more than a single item in semantic memory to be activated prior to presentation of a target.

Our finding of a divided attention effect for exemplar generation, but not for category verification, is consistent with a somewhat different version of the multiple versus single correct response hypothesis-namely, one that substitutes response production for multiple responses and identification or verification for single responses (Fleischman \& Gabrieli, 1998; Gabrieli et al., 1994). Unfortunately, this version, too, meets with difficulties. For instance, word-stem completion and word-fragment completion both involve response production, but only the former shows a reduction in priming following study under divided attention conditions. Word naming involves response production, but search demands are minimal in these tasks; still, priming in word naming is reduced by distraction during study.

In short, evidence from our own and other laboratories has demonstrated a difference in susceptibility to levels of processing and distraction during study for priming in the exemplar generation and category verification tasks. Moreover, it is increasingly evident that the encoding requirements of purportedly conceptually and perceptually driven indirect memory tasks vary not only between but also within classes. We do not as yet have a satisfactory theoretical explanation of our findings. They do, however, suggest that it will be necessary to redefine the criteria for classifying priming tasks as conceptual, to acknowledge that the operational and intuitive definitions of conceptual-priming tasks do not coincide, or both.

\section{Conceptual Priming in Young and Older Adults}

The present results join those from previous investigations in suggesting few age differences in conceptual priming, at least for exemplar generation. In Experiment 1 , if anything, we observed slightly more priming on this task for older adults than for young adults. Following procedures recommended by Hedges and Olkin (1985), we found the effect size for age differences in Experiment 1 to be moderate in size but negative $(d=$ -0.31 , with a $95 \%$ confidence interval from -0.88 to 0.26 ). The evidence is more ambiguous with regard to category verification. In Experiment 2, we found no priming for older adults under conditions that produced reliable priming in young adults, whereas in Experiment 3, the age difference in priming was not reliable. The effect sizes for these two experiments are 0.51 , with a confidence interval from 0.04 to 0.98 , and 0.26 , with a confidence interval from -0.31 to 0.83 , for Experiments 2 and 3 , respectively. As was discussed earlier, we have no ready explanation for the discrepant outcomes of Experiments 2 and 3 but are inclined to view the outcome of Experiment 2 as an anomaly. By contrast, the effect sizes for direct memory tasks were 0.76 , with a confidence interval from 0.17 to 1.34, for cued recall in Experiment 1, 0.87 , with a confidence interval of 0.39 to 1.36 , for recognition in Experiment 2, and 0.14, with a confidence interval from -0.42 to 0.71 , for recognition in Experiment 3 . The small Experiment 3 effect size merely reflects ceiling effects in hit rates $(.88$ for the young and .91 for the old).$^{5}$ The work reported here is thus consistent with the view that performance on indirect measures of memory is relatively constant across age, whereas performance on direct measures declines more.

What, then, are we to make of arguments that older adults are impaired in conceptual priming? Jelicic's (1995) claim was based on a review of studies using homophone-spelling tasks, in which age differences are sometimes but not invariably observed, and exemplar generation tasks, with one of the studies reviewed find- 
ing an age effect and the other not. Rybash (1996) also included only a small number of paradigms under the heading of conceptual-item priming-namely, homophone spelling, word-fragment completion, and wordstem completion. In the homophone-spelling task, participants hear one member of word pairs that sound alike (e.g., cell vs. sell) but have different meanings in contexts that bias one of these meanings, and are then asked to spell these words. Priming is defined as an increased likelihood of spelling the homophone in accordance with the biased meaning. Classification of homophone spelling as a conceptual- or perceptual-priming task is problematic, inasmuch as it is unclear that modality effects can be meaningfully studied in this paradigm, because the nature of the task appears to require initial auditory presentation. This task is also prone to explicit contamination effects (see La Voie \& Light, 1994). It is for these reasons that we did not include homophone spelling in our discussion of conceptual-priming tasks. Classification of word-fragment completion and word-stem completion as conceptual-priming tasks is also problematic. Because priming in these two tasks is relatively insensitive to level of processing but is affected by modality changes between study and test, they are generally classified as perceptual tasks (e.g., Roediger et al., 1992).

Since completion of the studies reported here, we have carried out an updated meta-analysis of priming studies comparing young and older adults that included 95 effect sizes from published studies (Light, Prull, La Voie, \& Healy, 2000). The mean weighted effect size was 0.185 , with a confidence interval from 0.133 to 0.237 , after six outliers were eliminated. This value is somewhat smaller than that reported by La Voie and Light (1994), but the failure of the confidence interval to include zero confirms the earlier conclusion of a small, but reliable, age difference in priming. We examined the consequences of partitioning the data in several different ways, some guided by suggestions of Roediger and McDermott (1993) and Fleischman and Gabrieli (1998). Most relevant to the present discussion, we pitted eight effect sizes for conceptual-priming tasks (word association, exemplar generation, and answering general knowledge questions) against perceptual-priming tasks (perceptual identification, lexical decision, picture naming, word and nonword naming, reading Turkish words, object decision, picturefragment completion, rhyme generation, word-fragment completion, word-stem completion, and anagram solution). The mean weighted effect size for the conceptualpriming tasks was 0.112 , with a $95 \%$ confidence interval from -0.041 to 0.265 , whereas that for perceptual-priming tasks was 0.226 , with a $95 \%$ confidence interval from 0.161 to 0.291 . Contrary to any hypothesis of impaired priming for conceptual tasks, there was no apparent age difference on such tasks, although the effect size for perceptual tasks was reliable. Note, however, that we did not include homophone spelling among conceptual-priming tasks; the effect size for this task was 0.754 , with a con- fidence interval from 0.434 to 1.075 , and the outcome of the comparison would have been different had this task been included. Task classification, then, is likely to be crucial in deciding the issue of whether conceptual priming is disproportionately impaired in old age, and, as was discussed above, task classification is not straightforward. Taken in conjunction with the failure of the conceptual/ perceptual distinction to discriminate between paradigms in which priming is sensitive to divided attention at study and tasks in which priming is insensitive to this manipulation, the data from cognitive aging suggest that this distinction may have outlived its usefulness.

In the meta-analysis, we also examined splits between production and identification tasks and between tasks deemed high and low in competition. Gabrieli and his colleagues (Fleischman \& Gabrieli, 1998; Gabrieli et al., 1994; Gabrieli et al., 1999) suggest that these distinctions are useful in differentiating priming tasks on which patients with Alzheimer's disease are impaired from those on which they are not. The question here is whether they are also useful in disaggregating priming tasks in comparisons of young and older adults. In our meta-analysis, these two classifications, which overlap considerably in their sorting of tasks, did indeed both produce reliable differences across effect sizes, with confidence intervals including zero for identification tasks and tasks designated low in competition. However, these groupings included a preponderance of tasks for which the dependent measure was latency, rather than accuracy or probability of response. The meta-analysis also suggested that effect sizes for latency measures are close to zero (mean weighted effect size $=0.072$ ), whereas those for other measures are more substantial (mean weighted effect size $=0.249$ ). The precise reasons for the difference between latency and other measures is not clear (see Light et al., 2000, for a discussion).${ }^{6}$ It is curious, then, that in the present Experiments 2 and 3, which used latency as a response measure, the direction of age differences favored the young. A goal for future research must be the identification of conditions governing age differences in indirect measures of memory. Our meta-analysis suggests some potentially fruitful directions in which to look.

\section{REFERENCES}

Anderson, N. D., Craik, F. I. M., \& Naveh-Benjamin, M. (1998). The attentional demands of encoding and retrieval in younger and older adults: 1. Evidence from divided attention costs. Psychology \& $\mathrm{Ag}$ ing, 13, 405-423.

Battig, W. F., \& Montague, W. E. (1969). Category norms for verbal items in 56 categories: A replication and extension of the Connecticut category norms. Journal of Experimental Psychology Monographs, 80(3, Pt. 2).

BLAXTON, T. A. (1989). Investigating dissociations among memory measures: Support for a transfer-appropriate processing framework. Journal of Experimental Psychology: Learning, Memory, \& Cognition, 15, 657-668.

Brown, A. S., \& Mitchell, D. B. (1994). A reevaluation of semantic versus nonsemantic processing in implicit memory. Memory \& Cognition, 22, 533-541. 
Cabeza, R. (1994). A dissociation between two implicit conceptual tests supports the distinction between types of conceptual processing. Psychonomic Bulletin \& Review, 1, 505-508.

Craik, F. I. M., Govoni, R., Naveh-Benjamin, M., \& Anderson, N. D. (1996). The effects of divided attention on encoding and retrieval processes in human memory. Journal of Experimental Psychology. General, 125, 159-180.

FISK, A. D., \& SCHNEIDER, W. (1984). Memory as a function of attention, level of processing, and automatization. Journal of Experimental Psychology: Learning, Memory, \& Cognition, 10, 181-197.

Fleischman, D. A., \& Gabrieli, J. D. E. (1998). Repetition priming in normal aging and Alzheimer's disease: A review of findings and theories. Psychology \& Aging, 13, 88-119.

FranCIS, W. N., \& KuČERA, H. (1982). Frequency analysis of English usage: Lexicon and grammar. Boston: Houghton Mifflin.

Gabrieli, J. D. E., Keane, M. M., Stanger, B. Z., KJelgaard, M. M. Corkin, S., \& Growdon, J. H. (1994). Dissociations among structural-perceptual, lexical-semantic, and event-fact memory systems in Alzheimer, amnesic, and normal subjects. Cortex, 30, 75-103.

Gabrieli, J. D. E., Stone, M. V., Shackleton, K., Thompson-Schill, S. L., LADD, S. L., VAIDYa, C. J., \& ChaRI, A. (1995). Attention and implicit memory for words. Manuscript submitted for publication.

Gabrieli, J. D. E., Vaidya, C. J., Stone, M., Francis, W. S., ThompSON-SChill, S. L., Fleischman, D. A., Tinklenberg, J. R., YesayAGE, J. A., \& WILSON, R. S. (1999). Convergent behavioral and neuropsychological evidence for a distinction between identification and production forms of repetition priming. Journal of Experimental Psychology: General, 128, 479-498.

Grober, E., Gitlin, H. L., Bang, S., \& BuschKe, H. (1992). Implicit and explicit memory in young, old, and demented adults. Journal of Clinical \& Experimental Neuropsychology, 14, 298-316.

HAMANN, S. B. (1990). Level-of-processing effects in conceptually driven implicit tasks. Journal of Experimental Psychology: Learning, Memory, \& Cognition, 16, 970-977.

Hamberger, M., \& Friedman, D. (1992). Event-related potential correlates of repetition priming and stimulus classification in young, middle-aged, and older adults. Journal of Gerontology: Psychological Sciences, 47, P395-P405

Hartley, A. A. (1992). Attention. In F. I. M. Craik \& T. A. Salthouse (Eds.), The handbook of aging and cognition (pp. 3-49). Hillsdale, NJ: Erlbaum.

HAWLEY, K. J., \& JOHNSTON, K. J. (1991). Long-term perceptual memory for briefly exposed words as a function of awareness and attention. Journal of Experimental Psychology: Human Perception \& Performance, 17, 807-815.

HEDGEs, L. V., \& OLKIN, I. (1985). Statistical methods for meta-analysis. San Diego: Academic Press.

IsingRINI, M., VAZOU, F., \& Leroy, P. (1995). Dissociation of implicit and explicit memory tests: Effect of age and divided attention on category exemplar generation and cued recall. Memory \& Cognition, $\mathbf{2 3}$, 462-467.

JACOBY, L. L., \& DALLAS, M. (1981). On the relationship between autobiographical memory and perceptual learning. Journal of Experimental Psychology: General, 110, 306-340.

JELICIC, M. (1995). Aging and performance on implicit memory tasks: A brief review. International Journal of Neuroscience, 82, 155-161.

Jelicic, M., Craik, F. I. M., \& Moscovitch, M. (1996). Effects of ageing on different explicit and implicit memory tasks. European Journal of Cognitive Psychology, 8, 225-234.

KELLOGG, R. T. (1980). Is conscious attention necessary for long-term storage? Journal of Experimental Psychology: Human Learning \& Memory, 6, 379-390.

Kellogg, R. T., Newcombe, C., Kammer, D., \& Schmitt, K. (1996). Attention in direct and indirect memory tasks with short- and longterm probes. American Journal of Psychology, 109, 205-217.

KORIAT, A., \& FEUERSTEIN, N. (1976). The recovery of incidentally acquired information. Acta Psychologica, 40, 463-474.

LA Vole, D., \& LigHT, L. L. (1994). Adult age differences in repetition priming: A meta-analysis. Psychology \& Aging, 9, 539-553.

Light, L. L., \& Albertson, S. A. (1989). Direct and indirect tests of memory for category exemplars in young and older adults. Psychology \& Aging, 4, 487-492.

Light, L. L., \& Prull, M. W. (1995). Aging, divided attention, and repetition priming. Swiss Journal of Psychology, 54, 87-101.

Light, L. L., Prull, M. W., La Voie, D. J., \& Healy, M. R. (2000). Dual process theories of memory in old age. In T. J. Perfect \& E. A. Maylor (Eds.), Models of cognitive aging (pp. 238-300). Oxford: Oxford University Press.

MACLEOD, C. M. (1996, July). Episodically enhanced word reading. Paper presented at the International Conference on Memory ICOM, Abano Terme, Italy

MaKI, P. M., \& KNopMAN, D. S. (1996). Limitations of the distinction between conceptual and perceptual implicit memory: A study of Alzheimer's disease. Neuropsychology, 10, 464-474.

McEvoy, C. L., Holley, P. E., \& Nelson, D. L. (1995). Age effects in cued recall: Sources from implicit and explicit memory. Psychology \& Aging, 10, 314-324.

Monti, L. A., Gabrieli, J. D. E., Reminger, S. L., Rinaldi, J. A., WilSON, R. S., \& Fleischman, D. A. (1996). Differential effects of aging and Alzheimer's disease on conceptual implicit and explicit memory. Neuropsychology, 10, 101-112.

Mulligan, N. W. (1997). Attention and implicit memory tests: The effects of varying attentional load on conceptual priming. Memory \& Cognition, 25, 11-17.

Mulligan, N. W. (1998). The role of attention during encoding in implicit and explicit memory. Journal of Experimental Psychology: Learning, Memory, \& Cognition, 24, 27-47.

Mulligan, N. W., \& Hartman, M. (1996). Divided attention and indirect memory tests. Memory \& Cognition, 24, 453-465.

Mulligan, N. W., \& Hornstein, S. L. (2000). Attention and perceptual priming in the perceptual identification task. Journal of Experimental Psychology: Learning, Memory, \& Cognition, 26, 626-637.

Nelson, M. J., \& DenNy, E. C. (1960). The Nelson-Denny reading test (rev. by J. I. Brown). Boston: Houghton Mifflin.

Park, D. C., Puglisi, J. T., \& Smith, A. D. (1986). Memory for pictures: Does an age-related decline exist? Psychology \& Aging, 1, 11-17

Park, D. C., Puglisi, J. T., Smith, A. D., \& Dudley, W. N. (1987). Cue utilization and encoding specificity in picture recognition by older adults. Journal of Gerontology, 42, 423-425.

Park, D. C., Smith, A. D., Dudley, W. N., \& Lafronza, V. N. (1989). Effects of age and a divided attention task presented during encoding and retrieval on memory. Journal of Experimental Psychology: Learning, Memory, \& Cognition, 15, 1185-1191

Parkin, A. J., Reid, T. K., \& Russo, R. (1990). On the differential nature of implicit and explicit memory. Memory \& Cognition, 18, 507-514.

PARKIN, A. J., \& Russo, R. (1990). Implicit and explicit memory and the automatic/effortful distinction. European Journal of Cognitive Psychology, 2, 71-80.

RABBiTT, P. M. A. (1982). How do old people know what to do next? In F. I. M. Craik \& S. Trehub (Eds.), Aging and cognitive processes (pp. 79-98). New York: Plenum.

RABBITT, P. [M. A.] (1984). How old people prepare themselves for events which they expect. In H. Bouma \& D. G. Bouwhuis (Eds.), Attention and performance $X$ : Control of language processes (pp. 515-527). Hillsdale, NJ: Erlbaum.

RAPPOLD, V. A., \& HASHTROUdi, S. (1991). Does organization improve priming? Journal of Experimental Psychology: Learning, Memory, \& Cognition, 17, 103-114.

Rastle, K. G., \& Burke, D. M. (1996). Priming the tip of the tongue: Effects of prior processing on word retrieval in young and older adults. Journal of Memory \& Language, 35, 586-605.

RATCLIFF, R., \& MCKoon, G. (1996). Bias effects in implicit memory tasks. Journal of Experimental Psychology: General, 125, 403-421.

RATCLIFF, R., \& MCKoON, G. (1997). A counter model for implicit priming in perceptual word identification. Psychological Review, 104, 319-343

RoEDIGER, H. L., III, \& MCDERMOTT, K. B. (1993). Implicit memory in normal human subjects. In F. Boller \& J. Grafman (Eds.), Handbook of neuropsychology (Vol. 8, pp. 63-131). Amsterdam: Elsevier.

Roediger, H. L., III, Weldon, M. S., Stadler, M. L., \& Riegler, G. L. 
(1992). Direct comparison of two implicit memory tests: Word fragment and word stem completion. Journal of Experimental Psychology: Learning, Memory, \& Cognition, 18, 1251-1269.

RYBASH, J. M. (1996). Implicit memory and aging: A cognitive neuropsychological perspective. Developmental Neuropsychology, 12, 127-179.

Salthouse, T. A. (1991). Theoretical perspectives on cognitive aging. Hillsdale, NJ: Erlbaum.

Schacter, D. L., Chiu, C.-Y. P., \& Ochsner, K. N. (1993). Implicit memory: A selective review. Annual Review of Neuroscience, 16, 159-182.

SCHMitTER-EDgecombe, M. (1996). The effects of divided attention on implicit and explicit memory performance. Journal of the International Neuropsychological Society, 2, 111-125.

Small, B. J., Hultsch, D. F., \& Masson, M. E. J. (1995). Adult age differences in perceptually based, but not conceptually based implicit tests of memory. Journals of Gerontology: Psychological Sciences \& Social Sciences, 50B, P162-P170.

SMith, S. M., \& Tindell, D. R. (1997). Memory blocks in word fragment completion caused by involuntary retrieval of orthographically related primes. Journal of Experimental Psychology: Learning, Memory, \& Cognition, 23, 355-370.

SRINIVAS, K., \& RoEDIGER, H. L., III (1990). Classifying implicit memory tests: Category association and anagram solution. Journal of Memory \& Language, 29, 389-412.

Vaidya, C. J., Gabrieli, J. D. E., Keane, M. M., Monti, L. A., GutierREZ-Rivas, H., \& Zarella, M. M. (1997). Evidence for multiple mechanisms of conceptual priming on implicit memory tests. Journal of Experimental Psychology: Learning, Memory, \& Cognition, 23, 1324-1343.

Vriezen, E. R., Moscovitch, M., \& Bellos, S. A. (1995). Priming effects in semantic classification tasks. Journal of Experimental Psychology: Learning, Memory, \& Cognition, 21, 933-946.

WELDON, M. S., \& JACKSON-BARRETT, J. L. (1993). Why do pictures produce priming on the word-fragment completion test? A study of encoding and retrieval factors. Memory \& Cognition, 21, 519-528.
Wolters, G., \& Prinsen, A. (1997). Full versus divided attention and implicit memory performance. Memory \& Cognition, 25, 764-771.

\section{NOTES}

1. Exemplar generation and category verification also differ in at least one other way. The dependent variable is response probability for the former and response latency for the latter. The majority of studies of the role of attention in priming have involved paradigms for which the dependent variable is response probability. As is shown by our review, these studies have not produced uniform results. The same is true for those few studies of divided attention in paradigms producing latencies as the dependent variable. Hence, study outcomes do not seem to cleave neatly into classes determined by response measures. Interestingly, as is discussed in the General Discussion section, there is some evidence that age differences are smaller for studies using latency measures than for those using other outcome variables.

2. Details of the analyses excluding participants who claimed to have guessed are available from the first author.

3. In Experiment 2, 2 young and 3 older adults claimed to have used study list information during the category verification task.

4. In Experiment 3,5 young and 3 older adults claimed to have used study list information during the category verification task.

5. For recognition, effect sizes were obtained for corrected recognition scores computed by subtracting false alarm rates from hit rates averaged across full and divided attention.

6. Proper interpretation of these statements requires a more complete appreciation of the classificatory schema used in the meta-analysis. Because reasonable people may disagree on classification criteria, readers are referred to Light et al. (2000) for details.

(Manuscript received May 21, 1997; revision accepted for publication July 23, 1999.) 